\title{
Kolonyal Söylem Aracı ve Mitler Gömüsü Olarak Bir Çizgi Roman Analizi: Tenten Kongo'da
}

\author{
A Comic Book Analysis as a Vehicle of Colonial Discourse \\ and Myth's Treasure: Tintin in the Congo
}

\section{Berhan ÖZDEMIR EROĞLU ${ }^{(*)}$}

\section{$\ddot{0} z$}

1929 yılında yayın hayatına başlayan Tenten dünya çapında oldukça sevilen ve bilinen bir çizgi roman karakteridir. Tenten akıll, zeki, cesur ve çok dürüst bir gazeteci gençtir. Tüm bu pozitif özelliklerine karşın Tenten karakterinin ırkçllı̆a varan önyargılara sahip olduğu göze çarpmaktadır. Bu makalede Fransız denemeci, eleştirmen ve göstergebilimci Roland Barthes'n Mythologies isimli eseri ışı̆̆ında, "mit analizi" yöntemi ile Tenten Kongo'da isimli macera incelenmiştir. Barthes'a göre çağdaş mitler karşımıza "kültürel inşa araçları" olarak çıkmaktadır. Yaratılan bu mitler, "öteki" ile "benlik" arasındaki farkı ustalikla hissettirerek bir söylem oluşturmakta ve propaganda amaçl kullanılmaktadır. Ayrıca Edward Said, Aime Cesaire, Frantz Fanon, Gayatri C. Spivak, Homi Bhabha gibi post-kolonyal teorisyenlerin de görüşlerinden faydalanılmıştır.

Anahtar Kelimeler: Kolonyalizm, Tenten, Barthes, Mythologies, Post-kolonyal Teori.

\section{Abstract}

The Adventures of Tintin was first published in 1929. Tintin is a well-known and beloved comic book character worldwide. He is smart, intelligent, courageous and

Özgün Araştırma Makalesi (Original Research Article)

Geliş Tarihi: 02.03.2020 Kabul Tarihi: 06.04.2020

(*) Öğr. Gör., Üsküdar Üniversitesi SHMYO Eczane Hizmetleri Programı, İstanbul Bilgi Üniversitesi Kültürel İncelemeler Yüksek Lisans Programı öğrencisi, berhan.ozdemir@ uskudar.edu.tr

ORCID ID: https://orcid.org/0000-0002-1024-846X 


\section{Berhan ÖZDEMIR EROĞLU}

also a very honest journalist. Despite all these positive features, it can be observed that Tintin has prejudices that lead to racism. In this article, the adventure named "Tintin in the Congo" has been examined with the method of "myth analysis" in the light of Mythologies, the work of the French literary theorist, philosopher, critic, and semiotician Roland Barthes. According to Barthes, contemporary myths appear as "the tools of cultural construction". These myths create a discourse and are used for propaganda purposes by highlighting the difference between "the Other" and "the Self". In addition, the ideas and views of postcolonial theorists such as Edward Said, Aime Cesaire, Frantz Fanon, Gayatri C. Spivak, and Homi Bhabha have also been used.

Keywords: Colonialism, Tintin, Barthes, Mythologies, Post-colonial Theory.

\section{Giriş}

Üsküdar University Journal of Social Sciences, 2020; issue: 10 , 157-183

Tenten yayın hayatına 10 Ocak 1929 tarihinde, Belçikalı Katolik bir gazete olan Le Vingtième Siècle'ın çocuk eki olan Le Petit Vingtième'de başlar. Yaratıcısı Georges Rèmi yani Hergé, çocukluk ve ilk gençlik yıllarında eğitimini Katolik bir okul olan Saint Boniface Enstitüsünde almıştır ve o yıllarda kendisi Katolik İzci Federasyonu'nun da bir üyesidir. İzci kampları sayesinde Avrupa'da çeşitli ülkelerde bulunmuş, bu da o yıllarda maceranın tadını almasını sağlamıştır. Tenten'den önce, izci bir çocukla ilgili maceralar kaleme almışsa da (Totor'un maceraları) Tenten ile zirveyi yakalamıştır. ${ }^{1}$

Tenten ideal bir Katolik genç olarak dizayn edilir; Avrupalıdır, başarılıdır, dürüsttür, sadıktır, arkadaşlarını asla arkasında bırakmaz, meraklıdır, araştırmayı sever, azimlidir, aksiliklerden asla yılmaz, her türlü aracı ustalıkla kullanır, köpeği, dostu ve macera arkadaşı Milou’ya çok bağlıdır. Bu pozitif özellikler yanında dikkatimizi çeken bazı unsurlar da bulunmaktadır; Tenten'in hiç bir kadınla ilişkisi olmamıştır. Serinin tek ana kadın figürü, Maria Callas'tan esinlenildiği söylenilen, Bianca Castafiore'dir ve karşımıza ilk kez serinin 8. kitabı "Ottokar'ın Asası" ile

${ }^{1}$ Jean-Marc Lofficier ve Randy Lofficier, Tintin (UK: Harpenden, Herts : Pocket Essentials, 2011), 9-19. 


\section{Kolonyal Söylem Aracı ve Mitler Gömüsü Olarak Bir Çizgi Roman Analizi: Tenten Kongo'da}

çıar. Sonrasında serinin tek daimi kadın figürüne dönüşmüştür. Ayrıca Tenten'in can dostu Kaptan Haddock'un alkole çok düşkün olmasına karşın Tenten alkol kullanmaz.

Tenten'in ilk serüveninin mekânı "Sovyetler Birliğï'dir. Batı Avrupalı bir gazeteci olarak Tenten, soğuk savaş döneminde, hayati koşulları yerinde görmek ve izlenimlerini yazıya dökmek üzere Sovyetler Birliği’ne gönderilir. İkinci kitap ise bu makalenin konusu olan Tenten Kongo'da isimli maceradır. Kongo o tarihte Belçika kolonisidir ve bağımsızlığını ancak 30 Haziran 1960'da elde edebilecektir. Bu nedenle, bu macera pek çok kolonyal göstergeye sahiptir. Hatta serinin bu kitabı içeriğindeki rrkçllk söylemleri nedeni ile bir kaç kez mahkemelik olmuştur. Bir insan hakları avukatı ve İngiliz vatandaşı olan David Enright, Britanya Irk Eşitliği Komisyonu'na (CRE) kitapla ilgili olarak şikâyette bulunmuştur. CRE'de kitapların satılmaması yönünde tavsiye kararı vermiştir. $\mathrm{Bu}$ nedenle İngiltere ve daha sonra da Amerika Birleşik Devletleri'ndeki birçok kitapçıda bu kitap, çocuk kitapları bölümünden kaldırılmış yetişkin kitapları bölümüne konmuştur. İsveç’te Kongo kökenli bir İsveç vatandaşı

Üsküdar Üniversitesi Sosyal Bilimler Dergisi, 2020;

sayl: 10 , $157-183$ olan Jean Dodou Monya, İsveç savcilığına kitapla ilgili şikâyette bulunmuş olsa da savcılık dava açılmaması lehine karar vermiştir. Belçika'da ise bir Kongo vatandaşı olan Bienvenu Mbutu Mondondo söz konusu macerayı mahkemeye vermiştir, lakin karar yine Tenten lehine sonuçlanmıştır. Bu davalar esnasında Vatikan'ın resmî gazetesinde, Katolik Tenten'i savunmak adına yazılar kaleme alınmıştır. ${ }^{2}$

Bu makalede, Hergéin “Tenten Kongo'da” isimli albümü, Roland Barthes' in Batı toplumunun hâkim sınıfının ürettiği mitleri analiz etmede kullandığı yöntemle incelenecektir. Dil içerisinde üretilen bu mitlerin nasıl ideolojik söylemlere dönüştüğü ele alınacaktır. Bu ideolojik söylemler kolonyal ve oryantalist söylemler çerçevesinde değerlendirilecektir. Ayrıca

\footnotetext{
${ }^{2}$ Aylin Aydı, "Çizgilerdeki Irkçılık," Ankara Üniversitesi Avrupa Toplulukları Araştırma ve Uygulama Merkezi e-bülten 4, say1:38, (Kasım 2011): 7.
} 


\section{Berhan ÖZDEMIR EROĞLU}

oluşturulan "öteki” kavramı üzerinden Batı’nın kendisini nasıl kurduğu, Tenten'in "beyaz kurtarıcı efendi” kimliği üzerinden, kolonileştirilmiş halkların ötekileştirilmesinin kitapta nasıl kurgulandığını göstermek amaçlanmıştır.

\section{Roland Barthes ve Mit Analizi}

Roland Barthes, Mythologies isimli eserinde Fransa'daki (kapitalist ve burjuva ideolojisinin hâkim olduğu bir toplum olarak) çağdaş mitlerin analizini yapmaktadır. Gündelik yaşamdaki göstergeleri (filmler, reklamlar, dergiler gibi popüler kültür nesneleri) inceler ve hâkim burjuva ideolojisinin bu göstergeler aracılığıyla nasıl yeniden üretildiğini

Üsküdar University Journal of Social Sciences, 2020; issue: 10 , 157-183 gösterir. Böylelikle çağdaş mitler karşımıza "kültürel inşa araçları" olarak çıkmaktadır. Mitler, hâkim ideolojinin ve burjuva değerlerinin "doğallaştırılması"na hizmet ederler ve böylece tarihi doğallaştırırlar. ${ }^{3}$ Barthes, bunun nasıl kurulduğunu şöyle açılar:

Burjuvazi kendi temel statüsüne sahip olmayan ve bu imajinasyonun dışında bu statüye erişemeyecek olan bütün bir insanlı̆̆ kendi ideolojisi içinde eritir ve bunun maliyeti de durağanlık ve bilincin yoksullaşmasıdır. Burjuvazi kendi temsillerini, küçük burjuva imgelerinin tüm sistematik alanlarna yayarak, toplumsal sinflar arasindaki hayalî eşitliği onaylar. ${ }^{4}$

Barthes'a göre "mit" herhangi bir söz olmayıp bir hitabettir, bir bildiridir, bir anlamlandırma biçimidir ama mitler de ölümsüz değildir, kendi tarihselliği içinde var olurlar. Mitlerin sadece "söz” olması gerekmez, yazılı olabilir veya gösterimlerden oluşabilir. Barthes buna örnek olarak meydan okumayı işaret eden bir ok örneği verir ve bunun da bir söz

${ }^{3}$ Roland Barthes, Mythologies (London: Vintage Books, 2009), 168. (Makale boyunca bu kitaptan yapılan bütün çeviriler yazara aittir.)

${ }^{4}$ A.g.e., 167. 


\section{Kolonyal Söylem Aracı ve Mitler Gömüsü Olarak Bir Çizgi Roman Analizi: Tenten Kongo’da}

olduğunu söyler. Resimler ve karikatürler de bu şekilde analiz yapmaya çok uygundur. Üstelik resmin yazıdan daha buyurgan olduğunu ve anlamı bize doğrudan verdiğini söyler. Barthes’a göre mitoloji, hem formel bilim olarak semiyolojinin (göstergebilim) hem de tarihsel bir bilim olarak ideolojinin alanına girmektedir. ${ }^{5}$

Semiyoloji, bir "gösteren ve gösterilen" ilişkisi üzerine kurulmuştur. $\mathrm{Bu}$ iki terimin bileşimi ise bir "gösterge" ye işaret etmektedir. Barthes bunu "parçayı bütüne bağlayan bağ” olarak açıklar. Bu üç terimin de tamamıla biçimsel (formal) ve herbirinin de değişikiçerikleri (content) olabileceğini belirtir. ${ }^{6}$ Mitler de, yukarıda bahsedilen bu üç boyutlu şablondan (gösteren, gösterilen, gösterge) oluşur lakin bu farklı ve özel bir yapıdır, kendisinden önceki semiyotik zincirden hareketle yeni bir semiyotik yapı kurulmuştur yani Barthes'in deyimiyle bu "ikincil bir semiyotik yapı"dır.? İlk yapıdaki "gösterge”, ikinci yapının yani mitin "gösteren”i durumundadır. Bu şablonu Barthes şöyle izah eder:

\begin{tabular}{|l|l|}
\hline $\begin{array}{l}\text { 1. gösteren } \\
\text { (signifier) }\end{array}$ & $\begin{array}{l}\text { 2. gösterilen } \\
\text { (signified) }\end{array}$ \\
\hline 3. gösterge (sign) & (SIGNIFIED) \\
1. GÖSTEREN (SIGNIFIER) & 2. GÖSTERILEN \\
\hline 3. GÖSTERGE (SIGN) & \\
\hline
\end{tabular}

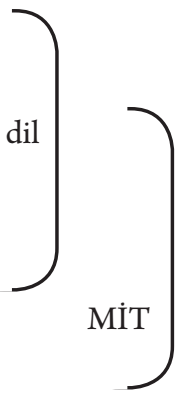

Üsküdar Üniversitesi Sosyal Bilimler Dergisi, 2020; sayl: 10 , $157-183$

Görüldüğü gibi mit kendini inşa etmek için dilsel yapının üzerine dayanmış ve ikinci bir dil olarak kendini yaratmaktadır ki Barthes buna üst-

\footnotetext{
${ }^{5}$ A.g.e.,131-135.

${ }^{6}$ A.g.e., 136.

${ }^{7}$ A.g.e., 137.
} 


\section{Berhan ÖZDEMIR EROĞLU}

dil (metalanguage) der. Bu üst-dilüzerine çalışıldığında artık dilsel şemaları dikkate almak gerekmez, sadece "mit"e katkıda bulunan total terimleri ve global göstergeyi tanımalı ve bilmelidir. ${ }^{8}$ Barthes, terminolojisini de şu şekilde oluşturur: Birinci semiyotik yapının son, ikinci semiyotik yapının (mit) ilk terimi olan "gösteren" i ise mitsel düzlemde "biçim" (form) olarak, dil düzleminde "anlam”(meaning) olarak tanımlar. Mitsel düzlemdeki "gösterilen" ise "kavram”dır (concept). Mitin üçüncü terimini ise "anlam yükleme, anlamlama” (signification) oluşturur ki bu terim bize bildiren, işaret eden, dikkatimizi çeken ve benimsetendir. ${ }^{9}$

Barthes’a göre biçim, anlamı yok etmez sadece eksiltir, anlam değerini yitirse de varlığını sürdürür, çünkü biçim, anlamdan beslenmektedir.

Üsküdar University Journal of Social Sciences, 2020; issue: 10 , 157-183 Barthes bunu şöyle açıklar: "Miti tanımlayan da zaten biçim ve anlam arasında sürekli tekrarlayan saklambaç oyunudur." ${ }^{10}$ Mit anlamı, biçime dönüştürmekte ve bir anlamda dili çalmaktadır. ${ }^{11}$ Kavram ise, miti dile getirendir, üstelik hem tarihseldir hem de bir maksat taşır. ${ }^{12}$ Değişik biçimler yolu ile kavramın sürekli tekrar edilmesi, bu maksadı ortaya koymaktaki ısrardan kaynaklanmaktadır. ${ }^{13}$

Barthes, kavramın biçimle ilişkisinde gizlenen bir durumun olmadığını ve bu nedenle "bilinçdışı"na ihtiyaç duymadığını belirtir, çünkü kendi deyimi ile "mit hiçbir şey saklamaz" "Mit bir değerdir ve "doğruluk" garantisi yoktur" ${ }^{15}$ der Barthes ve ekler "mit buyurgandır ve kafa ütüleyen

\footnotetext{
${ }^{8}$ A.g.e., 138.

${ }^{9}$ A.g.e., 140.

${ }^{10}$ A.g.e., 142.

${ }^{11}$ A.g.e., 156.

${ }^{12}$ A.g.e., 142.

${ }^{13}$ A.g.e., 143-144.

${ }^{14}$ A.g.e., 145.

${ }^{15}$ A.g.e., 147.
} 


\section{Kolonyal Söylem Aracı ve Mitler Gömüsü Olarak Bir Çizgi Roman Analizi: Tenten Kongo'da}

bir karakterdedir." ${ }^{16}$ Mitsel anlam yükleme hiç bir zaman keyfi ve rastgele olamaz, her zaman bir motivasyonu, bir nedeni bulunmaktadir. ${ }^{17}$

Bu bağlamda Barthes'in da söylediği gibi Tenten Kongo'da analizini mitsel olarak ele almak uygundur. Tenten, hem resim hem de yazı içeren bir tür olarak mitleri her iki şekilde üretmekte, hatta resmin yazıdan daha buyurgan olma karakteri ile kendini doğrudan bize açmaktadır.

\section{Kolonyalizm ve Kolonyal Söylem}

"Meşruiyet" hâkim güç için bir problem alanı olmuştur. 19. yüzyıla kadar meşruiyetini Tanrı'nın yeryüzündeki temsilcisi sıfatıyla Tanrı'dan alan yönetici sınıf ( $\mathrm{kral}$ ), aydınlanma dönemi ve sanayi devrimi neticesinde meşruiyetini halktan almaya başladığı andan itibaren "icraatları meşru gösterme" durumu ile karşıı karşıya kalmışıı ve bu durum propaganda aracı olarak "söylem"e başvurulmasını zorunlu kılmıştır. Merkezî iktidar, hem kendi halkına hem de kolonize ettiği coğrafyaların halklarına, empoze ettiği kendi değerler sistemi sayesinde "hâkim güç" olabilmektedir. ${ }^{18}$

Öncelikle "kolonyalizm nedir" sorusuna yanit aramak gerekirse, birbiriyle karıştırılan "emperyalizm" kavramı ile birlikte ele almak sağlıklı olacaktır. Oxford English Dictionary'de kolonyalizm şu şekilde açıllanır: "Başka bir ülke üzerinde, yeni yerleşimcilerle işgal ederek, tam veya kısmi siyasi kontrole sahip olma ve ekonomik açıdan sömürme politikası veya uygulaması" ${ }^{19}$ Robert Young Postcolonialism: An Historical Introduction isimli eserinde emperyalist ve kolonyalist imparatorluklar ayrımına değinir. Emperyalist imparatorluk ideolojik ve ekonomik nedenlerle merkezden yönetilen bir sisteme dayanırken, kolonyalist yönetim, merkezden uzak bölgelerde, ekonomik sebeplere dayanan pragmatik faaliyetler bütünüdür

\footnotetext{
${ }^{16}$ A.g.e., 148.

${ }^{17}$ A.g.e., 150.

${ }_{18}$ Terry Eagleton, İdeoloji, çev. Muttalip Özcan. (İstanbul: Ayrıntı, 1996), 23-24.

${ }^{19} \mathrm{https}$ // en.oxforddictionaries.com/definition/colonialism (son erişim: 15.02.2020) (Çeviri yazara aittir.)
}

Üsküdar

Üniversitesi

Sosyal Bilimler

Dergisi, 2020;

sayl: 10 ,

157-183 


\section{Berhan ÖZDEMIR EROĞLU}

ki, uzak coğrafyalara farklı toplulukları yerleştirmek ya da şirketlerin ticari amaçları doğrultusunda oluşturulan faaliyetlerdir bunlar. Emperyalizmde ise merkezî bir devlet politikası güdülerek, imparatorluğun gücü şatafatlı projelerle sürdürülür. ${ }^{20}$

Kolonyalizm dünyanın farklı bölgelerinde, farklı coğrafyalarda, farklı kültürlerle karşılaşmalardan ibaret değildir sadece, farklı süreçlerden geçmiş, farklı travmalara neden olmuştur. Marx kolonyalizmi eski ve yeni olarak ikiye ayırır: Eski kolonyalizm dönemi kapitalizm öncesidir, yeni kolonyalizm ise kapitalizmin oluşmasını sağlamıştır. Modern kolonyalizm, eskiden olduğu gibi sadece zenginlik elde etmeden fazlasını yaparak, yeni kolonilerin ekonomilerini kapitalist sistemde yeniden düzenlemiş, her iki ekonomi arasında çift yönlü bir akış başlatmıştır. Kolonize edilen

Üsküdar University Journal of Social Sciences, 2020; issue: 10 , 157-183 ülkelerden hammadde ve köleler sayesinde kaynak ve emek sağlanırken, diğer yönde koloniler bir pazar haline dönüştürülmüş böylece elde edilen kâr her iki şekilde de kolonize edenlerin olmuştur. ${ }^{21}$ Marksist düşünürlerin büyük bir kısmı kapitalizmi ve kolonyalizmi eş zamanlı düşünürken, kolonyalizmi zorunlu bir evre olarak da görmektedirler. Bu düşüncede Marx'ın India Under British Rule isimli makalesindeki son satırları oldukça etkili olmuştur:

İnilterénin, Hindistan'daki bu toplumsal devrime neden olan, aşağıll $k$ çıkarlarla hareket ettiği ve bunu başarmak için aptalca davrandığ doğrudur. Ancak konu bu değil. Asıl soru şu: İnsanlik, Asya'da temel bir toplumsal devrim olmaksizin misyonunu yerine getirebilir miydi? Bu soruya hayır diyorsak, İngiltere, işlediği suçlar ne olursa olsun, bu devrime neden olmakla, tarihin bilinçsiz bir aleti olmuştur.22

\footnotetext{
${ }^{20}$ Robert Young, Postcolonialism: An Historical Introduction (UK: Blackwell Publishers, 2001), 16-17.

${ }^{21}$ Ania Loomba, Kolonyalizm - Postkolonyalizm, çev. Mehmet Küçük. (İstanbul: Ayrıntı, 2000), 21.

${ }^{22}$ Karl Marx, "India Under British Rule,” Labour Monthly vol. 7 içinde, (Aralık 1925): 722. (Çeviri yazara aittir.)
} 


\section{Kolonyal Söylem Aracı ve Mitler Gömüsü Olarak Bir Çizgi Roman Analizi: Tenten Kongo’da}

Kolonyalizm ile emperyalizm arasındaki ayırıcı özellik olarak "kapitalizm" in belirlenmesi Leninist tanımdan da kaynaklanmaktadır. Lenin'e göre Batılı ülkeler, sanayiden kaynaklı büyüme sayesinde bir sermaye fazlalığı yaratmış, lakin yurtiçinde emeğin sınırlı olması nedeniyle Batı gözünü kolonize edebileceği ve emeğini sömürebileceği coğrafyalara çevirmiştir. Kapitalizm büyümesini ve gelişmesini hızlandırabilmek için dünyanın geri kalanına ihtiyaç duymaktadır. Bu küresel sistem "emperyalizm" olarak adlandırılır. ${ }^{23}$ Kolonilerin bağımsızlıklarını kazanmasından sonra emperyalizm çökmüş gibi görünse de, politik denetimler, ordu - silah güçleri ve ekonomik bağımlılıklar, günümüzde doğrudan bir denetim uygulayamasa da yine de dolaylı yollardan mevcudiyetini göstermektedir. Emperyalizm kolonilerin namevcudiyeti halinde işlemeye devam etse de, kolonyalizm işleyemez. Yenidünya düzeninde emperyalizm doğrudan egemenlik kuramadığı için, bunu kültür - ekonomi - politika üçgeninde devam ettirmektedir.

Siyahi kimliğin sahiplenilmesi ve özüne dönülmesi hareketi olan Negritude'un kurucularından olan Aime Cesaire Discourse on Colonialism isimli çalışmasında, kolonyalizmin ne olduğu sorusunu sorar ve yanıtlar:

Üsküdar Üniversitesi Sosyal Bilimler Dergisi, 2020; sayl: 10 , $157-183$

Sömürgecilik esasen nedir? Ne olmadiğı üzerinde anlaşmak gerekirse: $\mathrm{Ne}$ Incil'i öğretmektir, ne hayırsever bir girişimdir; ne (/) cehaletin, hastalıkların ve tiranliğın sinırlarm geriletme arzusudur, ne Tanrinın yüceltilmesi için üstlenilen bir projedir, ne de hukuk düzenini genişletme çabasıdır. Sonuçlarından çekinmeksizin, ilk ve son kez olmak üzere kabul etmeliyiz ki, buradaki tayin edici aktörler serüvenci ve korsan, toptancı ve gemi sahibi, altın arayıcısı ve tüccar, hirs ve güç ve bunlarm da gerisinde, içsel nedenlerden dolayı, tarihin belli bir noktasinda, birbirine rakip ekonomileri arasindaki rekabeti dünya ölçeğinde yaymaya kendisini zorunlu hisseden bir medeniyetin şeytani gölgesidir. ${ }^{24}$

${ }^{23}$ Loomba, Kolonyalizm, 23.

${ }^{24}$ Aime Cesaire, Sömürgecilik Üzerine Söylev: Fransız Irkçılı̆ııın Fikri Tarihsel Temelleri, 


\section{Berhan ÖZDEMIR EROĞLU}

Cesaire, kolonize eden ve edilen arasında hiçbir insani ilişki olamayacağının altını çizer. Sömürgeciliğin, kolonize edilen halkları bir üretim aracına dönüştürdügünü, insan sıfatından çıkarıp nesneleştirdiğini ve bu durumun kolonize edenleri de alçalttığını yazar. Bunu şöyle formüle eder: Kolonileştirme/Sömürgeleştirme $=$ Şeyleştirme (thingification). ${ }^{25}$ Burada Marx'ın kapitalist düzende para ve metanın nasıl insan ile özdeşleştirildiğine ve nasıl onun yerini aldığına ve insanın böylelikle nesneleştirildiğine dair saptamasının etkileri görülmektedir.

Üçüncü dünyanın Marx’ı olarak adlandırılan Frantz Fanon (Cesaire'in öğrencisidir.), kolonize edilen toplumun kendi değerlerinden uzak tutulması ve hatta kolonize edenler tarafından bu değerlerin hiçe sayılması ile kendi yerelliklerinin yok edildiğini söyler, böylece yerlinin ahlak

Üsküdar University Journal of Social Sciences, 2020; issue: 10 , 157-183 kurallarının olmadığı ve değersiz oldukları ilan edilmiş olur. Aynı zamanda kendi yerelliklerinin yok edilişi, yereli boşlukta bırakarak ruhlarında bir aşağılık kompleksine neden olmaktadır. ${ }^{26}$ Fanon, Yeryüzünün Lanetlileri (The Wretched of the Earth) isimli eserinde irk ve sinıfsal ayrımcilığ şu şekilde açıklar: "Sömürgelerde ekonomik altyapı aynı zamanda bir üstyapıdır. Neden, sonuçtur: Beyaz olduğunuz için zenginsiniz, zengin olduğunuz için beyazsınız."

$\mathrm{Bu}$ noktada Antonio Gramsci'nin "hegemonya” kavramı oldukça önem teşkil etmektedir. Hegemonya; yönetici gücün, yönettiği kitlenin rızasını alarak yönetmektir ve ideolojiden farklıdır çünkü ideoloji zorla dayatılabilir. Hegemonya ideolojiden daha geniş bir çerçeveye sahiptir, ideolojiyi de kapsar niteliktedir. Rızanın sağlanabilmesi için, hegemonik aygitlar devreye girer. Gramsci, hegemonik aygitları sivil toplum alanı ile ilişkilendirir. Bu alan aile, medya, kiliseler, okullar, ordu vs. olarak görülür.

çev. Güneş Ayas. (İstanbul: Doğu Kütüphanesi, 2005), 66-67.

${ }^{25}$ A.g.e., 77.

${ }^{26}$ Loomba, Kolonyalizm, 42.

${ }^{27}$ Frantz Fanon, Yeryüzünün Lanetlileri, çev. Şen Süer. (İstanbul: Versus, 2007), 46. 


\section{Kolonyal Söylem Aracı ve Mitler Gömüsü Olarak Bir Çizgi Roman Analizi: Tenten Kongo’da}

Hâkim güç, kendi dünya görüşüne gönüllü olarak rıza gösteren bir toplum yaratarak tahakküm kurar ve meşruiyetini bu şekilde kurar. ${ }^{28}$ Bazı tarihçiler kolonyal sistemi kolonileştirilen toplumların rızasını almadan, dayatılan bir süreç olduğunu söylese de, bazıları en dayatmacı durumlarda bile işbirliği yapan, kısmen gönüllü, kısmen de yapay bir rıza ile bunun sağlandığının altını çizer. ${ }^{29}$ Hegemonya "sürekli yenilenmesi, yeniden yaratılması, savunulması ve değişikliğe uğratılması gereken" ${ }^{30}$ bir dinamiktir ve bu nedenledir ki mitlere ihtiyaç duymaktadır. Böylece kurulan bilgi-iktidar ilişkisi “kolonyal iktidar”

Foucault'nun "bilginin masum olmayıp iktidarın işlemleriyle doğrudan bağlantılı olma” analizinden etkilenen Edward Said, "kolonyal söylem - oryantalist/şarkiyatçı söylem” incelemelerini Şarkiyatçılık isimli eserinde ele alır. Foucault'nun söylem analizinden hareketle, Aydınlanma dönemini takiben Avrupa'nın Şark’1 imgesel olarak üretip yönetebilmesini sağlayan söylemleri analiz eder ve Avrupa'nın kimliğini ve gücünü, Şark imgelemi karşısında nasıl kurduğunu göstermeye çalışır. Said, Gramsci’nin hegemonya kavramını zorunlu bir kavram olarak ele alır ve Şarkiyatçılığın kalıcı gücünü bu kavram çerçevesinde sağladığını söyler. Avrupalı olmayan kültürlerin ve halkların, Avrupalı olanlarla karşılaştırıldığında, "Avrupalı kimliğinin üstünlüğü” mitini sağlayan şey de hegemonyanın bir izleğidir. Şarkiyatçı söylemin nasıl üretildiği şöyle ifade eder:

(...) düpedüz farkl bir dünyaya yönelik, belirli bir anlama, kimi durumda denetleme, değisstirme, hatta şekillendirme istencinin ya da niyetinin dile getirilişi olmaktan öte, bu istencin, niyetin ta kendisidir; tüm bunlarm ötesinde, kesinlikle doğal halindeki siyasal iktidarla doğrudan, karşıllklı bir ilişki içinde olmayan, çeşitli iktidar türleriyle gelgitli bir alşverişte üretilip var olan, bir yere kadar, siyasal iktidarla,

\footnotetext{
${ }^{28}$ Eagleton, İdeoloji, 162-167.

${ }^{29}$ Loomba, Kolonyalizm, 50.

${ }^{30}$ Eagleton, İdeoloji, 166.
}

Üsküdar

Üniversitesi

Sosyal Bilimler

Dergisi, 2020;

sayl: 10 ,

157-183 


\section{Berhan ÖZDEMIR EROĞLU}

düşünsel iktidarla, kültürel iktidarla, ahlaki iktidarla alşverişinde biçimlenen bir söylemdir. ${ }^{31}$

Said, Barthes'in "mit” analizinden hareketle "Şarklının sabit, durağan, araştırmaya hatta kendi hakkında bilgi edinmeye gereksinimi olan bir şey olarak sunulması"na ${ }^{32}$ dikkat çeker ve Şarklının bir "malumat kaynağı", şarkiyatçının ise bir "bilgi kaynağı" olarak gösterilmesinin altındaki ilişkinin bir iktidar-bilgi ilişkisinden kaynaklandığını belirtir ve bu ilişkiyi Barthes'in şu cümleleri ile pekiştirir: "Bir söylen (mit) ve bu söyleni sürdürenler, kendilerini hiç durmaksızın türetebilirler.” ${ }^{33}$

Günümüzde kolonyal söylem incelemeleri sadece bilgi-iktidar ve tahakkümilişkileriüzerinden incelenmemekte, sömürge halklarının direniş

Üsküdar University Journal of Social Sciences, 2020; issue: 10 , 157-183 mücadelelerini de incelemektedir. Spivak, "Can the Subaltern Speak?” adlı makalesinde "madun" kavramını feminist ve Marksist çerçevede ele alır. Bu çalışmada Spivak "öteki” söyleminin bir "epistemolojik şiddet” olduğunu vurgular ve bunun tahakküm mekanizmalarının işleyebilmesi için bir "sessizleştirme" olduğunu belirtir. ${ }^{34}$ Cinsiyetçilik ve sınıf kavramlarını unutmadan "öteki" bilincine dair analizler yapar. Homi Bhabha ise "taklitçilik" kavramı üzerinde durur ve taklit etmenin bile "varlıklarının bir kinayesi” olarak bir direniş aracına dönüşebileceğini savunur. ${ }^{35}$ "Neredeyse aynı fakat tamamen aynı olmayan öteki” taklit yolu ile kolonyalizme direnmektedir.

Kolonyal söylem incelemeleri, ekonomik, kültürel, siyasal, düşünsel süreçlerin nasıl biçimlendirildiğini ve dönüştürüldüğünü ve söylem-

\footnotetext{
${ }^{31}$ Edward W. Said, Şarkiyatçılık, çev. Berna Yıldırım. (İstanbul: Metis, 2016), 22.

${ }^{32}$ A.g.e., 322.

${ }^{33}$ A.g.e..

${ }^{34}$ Gayatri C. Spivak, “Can the Subaltern Speak?” (1988): 76-78, son erişim: 15.02.2020, http://abahlali.org/files/Can_the_subaltern_speak.pdf

35 Homi Bhabha, "Of Mimicry and Man: The Ambivalence of Colonial Discourse,” October 28 (1984): 130, https://dx.doi.org/10.2307/778467
} 


\section{Kolonyal Söylem Aracı ve Mitler Gömüsü Olarak Bir Çizgi Roman Analizi: Tenten Kongo’da}

tahakküm ilişkilerini, kolonileştirilen halklar hakkında üretilmiş ve klişeleşmiş imgelerin, mitlerin tüm bu tahakkümü kurmada nasıl rol aldığını ele almaktadır. Bu çerçevede Herge'in Tenten Kongo'da isimli eserini Barthes'in mit analizi ve kolonyal söylem çerçevesinde ele alalım.

\section{Tenten Kongo'da: Mit ve Kolonyal Söylem Analizi}

7'den 70'e milyonlarca okuyucuya sahip Tenten, yaklaşık bir yüzyıldır sayısız çocuğun hayal gücünü tetiklemiş ve etkisi altında bırakmıştır. Toplam 112 dile çevrilmiş olduğundan etki alanı oldukça geniştir. $\mathrm{Bu}$ nedenle Tenten'in imajı ve maceralarının verdiği mesaj oldukça önem arz etmektedir. Tenten'in ilk yayımlanmaya başladığı dönemdeki dayandığı politik zemini Tom McCarthy Tenten ve Edebiyatın Gizemi isimli eserinde şöyle açıklar:

Tenten'in politik kökenleri en hafif deyişle sağdadır. Petit Vingtième katı bir Katolik gazetesiydi ve Hergènin Numa Sadoul'a bizzat söylediği gibi 'Katolik' demek o zamanlar 'anti-bolşevik' demekti. Ayn zamanda antisemitik anlamina da geliyordu. Yayın yönetmeni Abbè Norbert Wallez, masasının üstünde Mussolini'nin imzalı bir fotoğrafını bulunduruyordu Yanında çalı̧an gazetecilerin çoğunun da Belçika faşizminin eşiğinde gezinen Rex partisiyle bağlantıları vardı. ${ }^{36}$

Üsküdar

Üniversitesi

Sosyal Bilimler

Dergisi, 2020;

sayl: 10 ,

$157-183$

5 Mayıs 1930'da yayımlanmaya başlayan bu macera 11 Haziran 1931'de sonlanır. Sonrasında yine Fransız dergisi Coeurs Vaillants'da (Cesur Yürekler) yayımlanır. Kitap, II. Dünya Savaşı sonrasında yeniden düzenlenir ve renkli olarak basılır. İçindeki bazı bölümler aldığı tepkiler üzerine kesintiye uğrar. ${ }^{37}$ (Tenten'in bir gergedanı dinamit ile patlatma sahnesi ve Milou'nun bazı konuşma balonları gibi)

\footnotetext{
36 Tom Mccarthy, Tenten ve Edebiyatın Gizemi, çev. Cihat Taşçığlu. (İstanbul: Notos, 2016), 47.

${ }^{37}$ Lofficier, Tintin, 40.
} 


\section{Berhan ÖZDEMIR EROĞLU}

Tenten'in kendisi başlı başına bir mittir. Genelde çizgi roman karakterleri gibi ne geçmişte ne de gelecektedir Tenten, çizildiği dönemin ruhunu yansitır. 20. yüzyılda yaşar, gazetecidir, maceraperesttir, teknolojik araç gereçleri etkin bir biçimde kullanmaktadır ve aynı zamanda Katolik değerlere de sahip bir kahramandır. Birinci Dünya Savaşı ertesinde oluşan travmanın ışığında maskülen kimliğin yeniden yapılandırılması ve savaştan dönmüş askerlerin büyük ölçüde istikrarsı ve kapitalist bir sanayi ekonomisine yeniden entegrasyon problemine "beyaz erkeğin üstünlügü” söyleminden hareketle ortaya çıkarılmış bir karakterdir. Batının "ebedi gençlik" sembolüdür. Kendi kimliğini ve saflığını kaybetmeden kötülerin karşısına çıkan ve mücadele eden, kendinizi kolaylıkla

Üsküdar University Journal of Social Sciences, 2020; issue: 10 , 157-183 özdeşleştirebileceğiniz bir "süper çocuk" olarak karşımıza çıkar. ${ }^{38}$

Kongo'daki macerasında Tenten muhabir olarak Belçika'nın o dönemde kolonisi olan Kongo' ya gönderilir lakin kendini bir anda Kongo'daki elmas ticaretine hâkim olmaya çalışan bir çetenin hedefinde bulur. Kötü adamlar ile giriştiği mücadeleden ise her zamanki gibi galip çıkar ve hikâye "mutlu son" ile biter. Hikâye kabaca böyle olsa da içindeki kolonyalist söylemler ve mitler açısından bir hayli yüklü bir içeriğe sahiptir. Hatta orijinal kapak sayfası bile içeriğinin habercisi niteliktedir. Tenten (beyaz "kâşif” giysileri içinde) ve köpeği Milou, uzakta bir noktaya dikkatle bakmaktadırlar. Tenten bir tüfek taşımaktadır. Arka planda bir leopar sinsice Tenten ve köpeğini izlemektedir. Afrika’nın siyahi imgesine karşı, kahramanımız beyaz giydirilmiş ve elindeki tüfekle çizilmiştir ve böylece beyaz olmanın üstünlügünü, teknolojik olarak da üstün olmasının avantajını bir tüfek imgesi ile kapak sayfasından bize yansitmaktadır.

Serüven boyunca tüm Kongoluların simsiyah ve maymuna benzer bir biçimde tasvir edilmiş olması hiç de masum değildir. Antropolojik

\footnotetext{
${ }^{38}$ Jean-Marie Apostolides, "Herge and the Myth of the Superchild," Yale French Studies, no. 111 (2007): 54-55, son erişim: 20.02.2020, www.jstor.org/stable/20479370
} 


\section{Kolonyal Söylem Aracı ve Mitler Gömüsü Olarak Bir Çizgi Roman Analizi: Tenten Kongo’da}

olarak insanlığın Afrika kıtasında ortaya çıkıp, evrimleşerek tüm dünyaya yayıldığı teorisi üzerinden Afrika halklarının bu şekilde dizayn edilmesi, primat atalarımızın bir göstergesi olarak yorumlanabilir. ${ }^{39}$ Ayrıca Tenten'in beyazlığına karşı Afrikalılar simsiyah resmedilerek bir kontrast oluşturulmuş ve Tenten'in tüm iyi özelliklerine karşı (akıllı, çalışkan, cesaretli, mücadeleci, ahlaklı gibi) Afrikalıların bu özelliklerden yoksun hatta buna kontrast biçimde (kitabın ilerleyen sayfalarında göreceğimiz gibi) "zeki olmayan, tembel, korkak, ahlaki değerleri zayıf”" olarak gösterilmesinin bir tezahürü olarak kurgulanmıştır. Afrikalılar bir noksanlıklar, yoksunluklar miti çerçevesinde ele alınmış (noksan insan, noksan akıl, noksan medeniyet, noksan güzellik, noksan cesaret, noksan çalışkanlık, noksan yetenek vb.) ve “öteki” bunun üzerine inşa edilmiştir. Psikanaliz ve göstergebilim teorilerini kolonyal söyleme uyarlayan Homi Bhabha bunu The Location of Culture isimli eserinde Freudyen bir biçimde ele alır ve Freud'un fetiş kavramı ile stereotip ve kolonyal söylem arasındaki ilişkiye dikkat çeker. Fetişizmi "farklılığın reddine neden olan, kastrasyon sorunu etrafında tekrar eden sahne" ${ }^{40}$ olarak açıklar ve arkaik bir afirmasyon olan bütünlük/benzerlik ile eksiklik/farklılıktan kaynaklanan anksiyete arasında bir oyun, bir bocalama olarak tanımlar. ${ }^{41}$ Freud'un terminolojisinde "Tüm erkekler penise sahiptir." ile "Bazıları penise sahip değildir." cümleleri, kolonyal söylemde “Tüm erkekler aynı deri/ırk/kültüre sahiptir." ile "Bazıları aynı deri/ırk/kültüre sahip değildir.” cümlelerine dönüşür. ${ }^{42}$ Tenten’de bu çatışma (eksilik, noksanlık/

\footnotetext{
${ }^{39}$ Nilanjan Chakraborty, "Not so Comical - Tintin, Popular Culture and the Othering of Spaces," The IUP Journal of English Studies Vol. XI, No. 1, (March 2016): 26.

${ }^{40}$ Homi Bhabha, The Location of Culture (London and New York: Routledge, 1994), 74, https://archive.org/stream/TheLocationOfCultureBHABHA/the\%20location\%20 of $\% 20$ culture $\% 20 \mathrm{BHABHA}$ _djvu.txt

${ }^{41}$ A.g.e.

${ }^{42}$ A.g.e..
}

Üsküdar

Üniversitesi

Sosyal Bilimler

Dergisi, 2020;

sayl: 10 ,

157-183 


\section{Berhan ÖZDEMIR EROĞLU}

varlık), stereotipe dönüşür ve çünkü bu kolonyal söylem için son derece hayatîdir. ${ }^{43}$

Hikâyenin biraz içine girerek daha detaylı bir şekilde inceleyelim: Tenten ve Milou, Kongo'ya gitmek üzere denize açıldıklarında kaçak yolcu Stowaway, Milou'yu tehdit olarak görür ve denize atar. Bunu gören "siyahi" bir miço (yine simsiyah, kocaman dudaklı çizilmiştir) Milou'ya şöyle seslenir: "Efendi köpek” ${ }^{44}$ ve yakalaması için can simidi atar. Bu sırada Tenten gelir ve miçoya Milou’yu kurtarmak için hiçbir şey yapmadığını söyleyerek çıkışır. Suya atlamaya hazırlanırken "İşte şimdi gerçek bir erkeğin ne yapacağını göreceksin” ${ }^{45}$ der ve suya atlar. Burada siyahilerin "yeteri kadar erkek” olmadığını söyleyerek noksanlığa yine

Üsküdar University Journal of Social Sciences, 2020; issue: 10 , 157-183 vurgu yapılmaktadır. Noksanlık miti üzeriden siyahilerin eksikliklerine vurgu yapılarak "beyaz adamın üstünlüğü” miti zihinlere işlenmektedir. Bunu Tenten’in Kongolu çocuk Coco ile tanıştığı bölümde de görürüz. Milou "Pek zekiye benzemiyor!" 46 diyerek Coco öznelinde Kongo halkının zekâ seviyesini aşağılar. Coco'nun zekâsının pek de parlak olmadığı hükmü sonrasında geçerlik kazanır, kaçak yolcu Stowaway çocuğu döver ve korkutarak Tenten' in kullandığı arabayı çalar. Coco görevi olan; arabaya göz kulak olma işini böylece başaramaz. Durumu ağlayarak Tenten'e anlatınca Milou şöyle der: "Biz etraftayken hiç kimse korkmasın." ${ }^{47}$ Korkusuz ve kurtarıcı beyaz adam miti su yüzüne çıkmıştır oysa çocuğu döven ve düzeni bozan da bir "beyaz efendi" dir.

Zekâları pek de parlak olmayan Kongolular konuşmakta güçlük çekmekte, tıpkı çocuklar gibi yarım yamalak konuşmaktadırlar. Oysa

\footnotetext{
${ }^{43}$ A.g.e., 75.

${ }^{44}$ Herge, Tintin in the Congo, (San Francisco: Last Grasp, 2002), 13, https://notendur. hi.is/ sok1/02\%20The\%20Adventures\%20Of\%20Tintin\%20In\%20The\%20Congo.pdf ${ }^{45}$ A.g.e., 14.

${ }^{46}$ A.g.e., 21.

${ }^{47}$ A.g.e., 26.
} 


\section{Kolonyal Söylem Aracı ve Mitler Gömüsü Olarak Bir Çizgi Roman Analizi: Tenten Kongo’da}

Kongoluların anadili, Fransızca yani Tenten'in konuştuğu dil değildir ve Afrikalının bilincinde Batı etkili bir kırılma söz konusu olduğundan başka bir dili kendi aksanları ile sakil konuşmaktadırlar. Bhabha açısından bakarsak bu şekilde konuşmak da bir direniş aracı olabilmektedir ve böyle konuşmak kolonyal düzene bir başkaldırı olarak okunabilmektedir.

Kongoluları çocuk gibi göstermek de bir amaca hizmet etmektedir. Avrupalı kolonyalistlerin kolonileşme faaliyetlerini meşru bir zemine oturtmak istemeleri modern ırkçıllğın temellerini atmıştır. Kont Joseph Arthur de Gobineau modern ırkçılı̆̆ın babası olarak bilinmekle birlikte " erkek - kadın - çocuk " hiyerarşi sıralamasını ırklara uygulamış, "Beyaz (Caucasian), Sarı (Mongoloid) ve Siyah (Negroid) “ şeklinde 3 temel ırk olduğunu belirterek; beyaz ırkın üstün zekâ, ahlak, cesaret, irade ve diğer tüm olumlu kalıtsal özelliklere sahip olduğu için batı etkisinin tüm dünyaya egemen olduğunu iddia etmiştir. Fikirleri, sonradan Nazi, Ku-Klux Klan ve Apartheid hareketleri ile devam etmiştir. ${ }^{48}$ Hiyerarşi sıralamasında erkek ve beyaz en üstte, çocuk ile siyah bir tutularak en altta bulunur. $\mathrm{Bu}$ da Afrikalı siyahları çocuk kategorisine indirgeyerek "yönetilmeye muhtaç oldukları"nın altını çizmektedir.

İlerleyen sayfalarda Tenten, beraberinde Milou ve Coco olduğu halde arabayla seyahat ederken bir tren araçlarına çarparve tren büyükzarargörür. Trende bulunan yolcular batılı şekilde giyinmiş Kongo'lulardır. Burada yine Bhabha'ya dönmek gerekmektedir. Kolonyal söylemler Bhabha'ya göre sabit kimlikler yaratamamış, kolonize edilenin melezleşmesi ile sonuçlanmıştır; bu da kolonyal söylemi alaşağı edebilir. ${ }^{49}$ Batılı tarzda giyinmek de bir direniş aracına dönüşebilmektedir. Taklit yine noksanlık mitinden el almakta, orijinalin noksan ve kusurlu bir kopyası haline dönüşen "öteki”, taklit ile bozguncu bir kimlik kazanabilmektedir.

\footnotetext{
${ }^{48}$ Anthony Giddens \& Philip W. Sutton, Sosyoloji, çev. Ayşe Nilüfer Durakbaşa, Funda Karapehlivan Şenel ve Senem Tüfekçioğlu. (İstanbul: Kırmızı, 2008), 533.

${ }^{49}$ Loomba, Kolonyalizm, 113.
} 


\section{Berhan ÖZDEMIR EROĞLU}

Hikâyenin devamında tren yolcularının hepsi aşağıya inerler ve durumdan şikâyetçi olurlar. Tenten "Susun!” ${ }^{0}$ diye emreder ve treni göstererek o çürük şeyi tamir edeceğini söyler. Yolcuları tembellikle suçlayarak çalıştırır, kendisi direktif verir. Burada da yine "tembel Afrikalılar” miti gözümüze çarpmaktadır. Beyaz adam emir veren ve yöneten konumundadır, Kongolular ise zorla çalıştırılması gereken tembeller topluluğudur. Tenten trenin motoru çalışmadığı için onu arabasıyla istasyona kadar çeker. Batı'nın yenilmez teknolojisi, “öteki”nin bakımsız teknolojisini mağlup eder.

Tren ve yolcularını istasyona bırakan Tenten yerlilerin taşıdığı bir tahtırevanla Ba Baoro’m kabilesinin yaşadığı köye götürülür. Omuzlarda taşınması hiyerarşik bir düzeni gösterir. Kolonyal imparatorluk Tenten'in

Üsküdar University Journal of Social Sciences, 2020; issue: 10 , 157-183 özelinde temsil edilmektedir. Kabile şefi Tenten’i “Hoş geldin asil yabancı"s1 diyerek karşılar. Tenten'e "Boulo Matari" yani "güçlü, beyaz, iyi adam” olarak hitap eder. Beyaz adamın asilliği ve güçlülüğü yerliler tarafından içselleştirilmiştir. Burada Gramsci'nin hegemonya kavramına dönüp bakarsak, hegemonik aygıtlar vasıtasıyla hâkim kılınan güç, kendi dünya görüşüne gönüllü olarak rıza gösteren bir kabile şefi yaratmış ve tahakkümünü bu şekilde kurmuştur. Durum aksine dönüp de Tenten kutsal bir putu çalmakla suçlanıp, ölüm cezasına çarptırıldığında yerlilerin bir çocuk kadar kolay kandırılabileceği ve hüküm vermekteki acziyeti ortaya konmuş olur. Akabinde hapisten kaçtığında yine teknoloji sayesinde suçsuzluğunu kanıtlar. Yanında getirdiği film makinesi ve fonograf sayesinde büyücü doktor ve Stonaway'in konuşmalarını kayda alır. Konuşmada büyücü doktor kabile insanlarını etkisi ve gücü altında tutmak için, onların cahil ve aptal kalmalarını sağlaması gerektiğini söyler. Büyücü doktor Tenten'i kendisine bir tehdit olarak görmektedir. Avrupa perspektifinden bakılırsa tıp bilimi Avrupa'nın mülkiyetindedir ve büyücü

\footnotetext{
${ }^{50}$ Herge, Tintin, 36.

${ }^{51}$ A.g.e., 38.
} 


\section{Kolonyal Söylem Aracı ve Mitler Gömüsü Olarak Bir Çizgi Roman Analizi: Tenten Kongo’da}

doktor bir şarlatandır. Afrika'nın inanç sistemi ise şeytani vudular, kara büyüler ile sınırlıdır, oysaki karşısında tek hakikat olan "Hristiyanlık" vardır.

Tenten’in kaçtığı anlaşılınca halk etrafını sarar. Tenten bir yumrukla büyücü doktoru yere serer ve etrafını tehdit eder: "Daha yakına gelmek isteyen varsa bekliyorum." ${ }_{22}$ "Beyaz adamın yenilmezliği, korkusuzluğu ve cesareti” miti tekrar gözümüze çarpmaktadır. Ses kaydını dinleyen ve Tenten'in çektiği filmi izleyen kabile üyeleri galeyana gelirler, kutsalları ile dalga geçen "büyücü doktora ölüm” diye bağırırlar. Tentenin kamerası onlara gerçeği göstermiş, aydınlanmanın sembolü haline gelmiştir. Eğitimsiz ve irrasyonel kabile halkı Tenten'in sorgulamasız üstünlüğünü kabul eder. Böylece kabile halkının nasıl kolayca manipüle edilebileceğini ve kolayca yönlendirilebileceğini görmüş oluruz. Tenten'den köyün şefi olmasını dizlerinin üstünde yere kapaklanarak isterler. Tenten kabul eder ve "köyünü” kolaçan etmeye çıkar. İki köylü birbiriyle bir şapka için kavga etmektedirler. Tenten köyde kavga istemediğini söyler ve kendine "Kral Süleyman”ı referans alarak onun adaletini uygulayacağını belirtir. Şapkayı ikiye böler böylece "adaleti” sağlar. İki köylü de bu adalet paylaşımından oldukça mutludur. Tenten'in ne kadar adaletli ve iyi bir beyaz olduğundan dem vurarak oradan ayrilırlar. Tenten köyde dolaşmaya devam eder ve bir kadın ağlaması duyar. Bunu üzerine kulübeye girer ve sebebini sorar. Kadın kocasının içine kötü ruh kaçtığını ve bu nedenle hastalandığını söyler. Tenten hastaya biraz kinin verir ve adam mucizevi bir şekilde iyileşerek ayağa kalkar. Kadın şaşırmıştır, yine dizlerinin üstüne çökerek yere kapaklanır ve şöyle der: "Beyaz adam çok iyi. Büyük efendi. O kocamı iyileştirmek. Beyaz efendi Boula Matari.” ${ }_{33}$ Barthes'ın dile getirdiği “mitsel anlam yüklemenin hiçbir zaman rastgele ve keyfî olamayacağı" ve "değişik

\footnotetext{
${ }^{52}$ A.g.e., 47.

${ }^{53}$ A.g.e., 51.
} 


\section{Berhan ÖZDEMIR EROĞLU}

biçimler yolu ile kavramın sürekli tekrar etmesi” ile sık sık Kongoluların dilinden "Beyaz efendi çok iyi, Boula Matari, asil yabancı vb.” sözcüklerinin yinelenmesi üzerinden mit kendini tekrar tekrar kurmaktadır.

$\mathrm{Bu}$ sırada Stowaway ve Muganga, Ba Baoro'm kabilesinin düşmanı olan M'hatavu kabilesinin şefine okla bir not yollarlar. Notta Ba Baoro'm kabilesinin büyük beyaz şefi olarak Tenten'in onlara savaş açtığ yazmaktadır. M'hatavu kabilesinin şefi küplere biner ve adamlarını toplar. Bu arada silahlı birliğinden şöyle söz eder: “Benim ordum Avrupa orduları gibi eğitimli ve silahlı, Ba Baoro'm kabilesini kolayca yeneceğiz." ${ }^{44} \mathrm{Bu}$ cümle Fanon'un işaret ettiği ruhlarında oluşturulan aşağılık kompleksinin göstergesidir. Üstün nitelikler yine Avrupalılara atfedilmiş ve bu da kabile

Üsküdar University Journal of Social Sciences, 2020; issue: 10 , 157-183 tarafından içselleştirilmiştir.

Savaş haberini alan Tenten tüm cesareti ve özgüveni ile çarpışmaya tek başına gider. Bir ağacın arkasına kuvvetli bir elektro mıknatıs yerleştir ve ağacın yanında beklemeye başlar. Karşı kabile savaşçılarının firlattığı her ok ve mızrak bir miknatıs sayesinde ağaca isabet eder. Bu duruma sinirlenen şef, tüfekten bozma topun getirilmesini ister ama ne var ki Tenten yerine kendilerini patlatırlar. Bu sırada Tenten onlara seslenir: “Babaoro'mla barış yapın ya da gazabımdan korkun”ss Tüm savaşçılar ona secde ederler ve Tenten'i M'hatavu kabilesinin şefi yaptıklarını söylerler, Tenten kabul eder. Beyaz adamın zekâsı ve teknolojisi yine galip gelmiştir. "Kudretli ve üstün beyaz adam” miti Barthes'in öngördüğü üzere sürekli yenilenmektedir.

O akşam Tenten leopar avına çıkmak ister. Bunu öğrenen Stowaway, Muganga'nın yanına koşar ve Tenten' in leopar avına çıkacağını duyduğunu ve bunun Tenten'i tuzağa düşürmek için iyi bir firsat olduğunu söyler. Muganga ona "Aniota" isimli gizli bir topluluktan bahseder. Beyazların

\footnotetext{
${ }^{54}$ A.g.e., 53.

${ }^{55}$ A.g.e., 55.
} 


\section{Kolonyal Söylem Aracı ve Mitler Gömüsü Olarak Bir Çizgi Roman Analizi: Tenten Kongo’da}

getirdiği “medeniyet” yanlısı siyah kabile şeflerini öldüren bu gizli cemaatin üyelerinin, leopar kılığına girerek ve ellerindeki sopalarla sahte leopar izi bırakarak kurbanlarını uykularında boğazlayarak öldürdüklerini söyler. Büyücü de leopar kılığına girerek Tenten'in işini bitirebileceğini söyler. Lakin leopar kılığına giren büyücü gece vakti bir boa yılanının saldırısına uğrar ve onu Tenten kurtarır. Büyücü kırık bir dille "Bırak kölen olayım asil beyaz adam”s6 diyerek minnettarlığını gösterir. Üstün ahlaklı beyaz adam, eksik ahlak sahibi düşmanının hayatını kurtarmış ve bir kahraman miti yaratmıştır.

Büyücü doktor suç ortağı Stowaway'in yerini gösterir. Tenten oraya ulaştığında saklanmış olan Stowaway, Tenten'in kafasına vurarak onu bayıltır. Görüldügü gibi Tenten'e zarar verebilen de yine sadece beyaz adamdır. Tenten'i bağlayarak bir ağaç dalına asar, sular yükseldiğinde, nehirdeki timsahlar Tenten’i yiyeceklerdir. Milou ise vahşi hayvanlara yem olmak üzere bayıltıldığı yerde bırakılmıştır. Bu sırada nehirden bir kurtarıcı gelir: Başka bir beyaz adam! Yakınlardaki misyoner merkezinin yöneticisi peder bir grup Kongolu çocukla geziye çımıştır. Peder Tenten'i timsahlardan, Tenten Milou'yu bir boa yılanından kurtarır ve kanoya binerek merkeze doğru yola çıkarlar. Kürekleri Kongolu çocuklar çekmektedir. Misyoner merkezinde peder etrafı Tenten'e tanıtır; hastane, tarım okulu, şapel ve de sınıflar. Bir sene önce buraya geldiklerinde etrafın hep çalılık olduğunu söyler. Yani medeniyet getirmişlerdir bu topraklara. Milou'nun söylediği ise çok manidardır: "En büyük Misyonerler!" ${ }_{57}$ Misyonerlikte görevli başka bir pederin rahatsızlanması neticesinde coğrafya dersini vermek Tenten'e düşer. Tenten derse başlar: "Sevgili arkadaşlarım, bugün size ülkeniz Belçika'dan bahsedeceğim.” ${ }^{88}$ Tenten'in

\footnotetext{
${ }^{56}$ A.g.e., 59.

${ }^{57}$ A.g.e., 66.

${ }^{58}$ A.g.e., 67.
} 


\section{Berhan ÖZDEMIR EROĞLU}

çocukların ülkesi olarak Kongo'dan değil de Belçika'dan bahsetmesi "kolonyal bakış açısı”nı gözümüze sokmaktadır. Gramsci'nin hegemonik aygitları kullanılarak (kilise ve okul), kolonize edilen toplum üzerindeki tahakküm mekanizmaları çalıştırılmaktadır.

Ders esnasında sınıfa bir leopar girer, Tenten ona tahtayı silmek için kullandığı süngeri atar ve leopar süngeri yer. Yere su döker, leopar içer ve şişen süngerin etkisiyle zavallı leopar acı içinde kalmıştır. Tenten ona elindeki sopa ile vurur ve tekmeleyerek sınıftan dişarı atar. Az sonra öfkeli bir Kongolu sınıfa dalar ve bağırır. Hayvanın evcil olduğunu, elinden yemek yediğini, şimdi acı içinde inlediğini ve bunun hesabını soracağını söyler. Kendisinin Büyük Amerikan Sirki’nin müdürü olduğunu ve isminin Jimmy Macduff olduğunu belirtir. Tenten ona kabaca bağırır: "Şimdi

Üsküdar University Journal of Social Sciences, 2020; issue: 10 , 157-183 sessiz ol ve söyleyeceklerimi dikkatlice dinle!" ${ }^{9}$ diyerek adamı azarlar ve onunla dalga geçerek, "Şimdi sınıfı usulca terk et!”"60 diye de emreder. Macduff Kongoludur ama Batılı bir biçimde giyinmiş ve beyaz adamın dilini konuşmaktadır. Beyaz adamdan tek farkı derisinin rengidir. İngiliz sömürgecisinin Hindistan'da kendi ürettiği özneye bakışını Bhabha şu şekilde açıllar: "not quite/not white" ${ }_{11}$ (beyaz değil, tam değil) Kongolu Macduff da sömürgecinin ürettiği bir öznedir, kılığı kıyafeti, dili Batılıdır ama yine de "beyaz" değildir, "tam" değildir. Bu da yine noksanlıklar miti üzerinden geliştirilen bir söyleme dönüşmüştür. Ders sonrası peder Tenten'e "uzaktaki ülkemiz"i anlattı̆̆ için teşekkür eder.

Albümün birçok yerinde Tenten’ in hayvanlara şiddet içeren davranışlar sergilediği de görülmektedir. Örneğin bir timsaha ateş eder kurşun ile alt edemeyince tüfeği hayvanın açık ağzına yerleştirir ve gider, antilop avına çıktığında üst üste ateş eder ve yaklaşık on kadar hayvanı öldürür, bir maymunu öldürür ve derisini giyer, aslanlara, leoparlara, maymunlara,

\footnotetext{
${ }^{59}$ A.g.e., 70.

${ }^{60}$ A.g.e..

${ }^{61}$ Bhabha, "Mimicry", 132.
} 


\section{Kolonyal Söylem Aracı ve Mitler Gömüsü Olarak Bir Çizgi Roman Analizi: Tenten Kongo'da}

fillere, bufalolara, yılanlara şiddet gösterir, hatta bir gergedanın sırtına dinamit yerleştirerek onu patlatır. "Öteki” ni kontrol etme ve evcilleştirme arzusu coğrafyanın hayvanlarına da sirayet etmiştir. Beyaz adamın tahakkümü altındaki "insan-olmayan" ya da "noksan/eksik insan" olarak canlılarla kurduğu ilişki, Cesaire'ı "kolonize eden ile edilen arasında hiç bir insani ilişkinin olamayacağı” düşüncesinin bir göstergesidir. Burada gördüğümüz bu düşüncenin; hayvanları nesneleştirerek ve içeriğinden yoksun bırakarak "şeyleştirilmesi" ise canlılara uygulanan orantısız şiddetin bir yansımasıdır. Tenten'in bu macerasında, "insan" ve "hayvanlar" da ("öteki”nin evcilleştirilmesinde ya da medenileştirilmesinde) aynı eğilime "şeyleştirme"ye maruz kalmaktadır.

Tenten'in pigmelerle karşılaşması da ilginçtir. Milou'yu kaybeden Tenten, onu ararken yerde çılak ayak izleri görür ve suçluyu tayin eder: Siyahi yerliler! Fanon'un ifade ettiği gibi: "Sömürgecinin yönettiği dünya karşısında sömürge halkı suçsuzluğu kanıtlanana kadarherzaman suçludur. Ama bu suçluluk sömürge halkının kabul ettiği bir suçluluk değildir, daha çok bir tür lanet olarak, Demokles' in kilıcı olarak görülür."르 Yerli bir çocuk gördüğ̈nü sanan Tenten ona arkadan yaklaşır lakin bu yaşlı bir pigmedir. Yaşıı pigme koşarak uzaklaşır, Tenten ise arkasından "korkak, tıpkı ırkı gibi”" ${ }^{3}$ der ve az sonra yaşlı pigme kabile üyeleri ile geri döner. Oysa barış̧̧ıl amaçlar taşımaktadırlar, Tenten’in ününü duymuşlar ve köye davet etmek istemişlerdir. Köye ulaştıklarında Milou kafasında bir taç ile tahtta onları bir kral edası ile beklemektedir. Beyaz efendinin köpeği bile yerlilerin efendisi konumundadır. Daha sonra olaylar çözülür ve tüm olayların elmas kaçakçllığ ile ilgili olduğu ve Tenten’i bu konuya bulaşmaması için her şeyi ünlü gangster Al Capone’un ayarladığı ortaya çıkar. Tenten kaçakçı çeteyi çökertir ve yine "kahraman" olur. Gazetelerde "Kongo Chicago’nun

\footnotetext{
${ }^{62}$ Fanon, Yeryüzünün Lanetlileri, 58.

${ }^{63}$ Herge, Tintin, 87.
} 


\section{Berhan ÖZDEMIR EROĞLU}

yeni kolonisi mi oluyor?" ${ }_{64}$ başlıklı yazılara rastları. $\mathrm{Bu}$, yabancı bir gangsterin kolonyal yönetimi tehdit etmesinin bir göstergesidir. $\mathrm{O}$ dönemde Avrupa'nın kolonilerini kaybetme korkusu ile yeni ve daha etkin bir güç olarak sahneye çıkan Amerika Birleşik Devletleri'nin yayılmacı göstergeleri Herge'i bu kareleri çizmeye yöneltmiştir.

Tenten'in Belçika'ya dönmesi ile Afrika'nın her yeri hüzne boğulur. Kitabın son sayfası Tenten'e bir güzelleme niteliğindedir. İki Kongolu arasında konuşur: "Belçika'daki tüm beyazların Tenten gibi olduğunu söylüyorlar." Bir yaşlı Kongolu etrafındakilere Tenten gibi güçlü bir beyaz adam görmediğini anlatır. Bir anne çocuğunu "iyi bir çocuk olmazsa, Tenten gibi olamayacağını” söyleyerek azarlar. Kongo’daki köpekler bile Milou'ya imrenmektedirler. Tenten'in ve Milou'nun totemi yapılmış ve

Üsküdar University Journal of Social Sciences, 2020; issue: 10 , 157-183 bir Kongolu ona secde etmektedir. Barthes' in "resmin buyurgan tavrı" bu karede göze çarpmakta, Tenten'in yarı-tanrı bir varlığa dönüştürülerek ona secde edilmesi ile "Batı üstünlüğ̈̈" sürekli yinelenmektedir.

\section{Sonuç}

Tenten karakteri, Edward Said'in de ifade ettiği gibi oryantalist bakış açısına sahip akademisyenler gibidir. Gazeteci kimliği ile önce Sovyetler Birliği’ne sonra Belçika Kongosu'na "gerçekleri” araştırmak için gitmiştir. Bu gerçek; Avrupa'nın Şark’a olan üstünlügünü kuran ve üreten, aynı zamanda üzerinde kolayca tahakküm kurulabilecek ve yönetilebilecek bir "öteki” yaratmaktır. Said'in deyişiyle "Şarkiyatçılıkta ortaya çıkan Şark, Şark’ı Batı bilgisine, Batı bilincine, sonra da Batı egemenliğine taşıyan bir güçler öbeği bütünü tarafından şekillendirilmiş bir temsil biçimleri dizgesidir." ${ }^{65}$ Sömürgeleştirilen insanlar ve sömürgeleştirenler arasında bir dikotomi oluşturulur: Sömürgeleştirilen insanlar mantık ve ahlak yoksunu, barbar, şehvet düşkünü, tembel olarak tanımlanırken, Avrupa

\footnotetext{
${ }^{64}$ A.g.e., 95.

${ }^{65}$ Said, Şarkiyatçllı, 215.
} 


\section{Kolonyal Söylem Aracı ve Mitler Gömüsü Olarak Bir Çizgi Roman Analizi: Tenten Kongo’da}

kendini akılcı, mantıksal, cinsel arzu ve isteklerini denetim altında tutan, çalışma ahlakına sahip, medeniyetin ta kendisi olarak kurar. Şarklının durağanlığına karşılık, Avrupa sürekli ilerleme kaydetmektedir. Şarklı "kadın" imgesine, Avrupalı "erkek" imgesine sahiptir. Bu da Tenten serüvenlerinde esas karakterler içinde kadın karakterlerin olmamasının bir yansıması gibidir.

Barthes'a göre mitler depolitize edildiği izlenimi uyandıran yani kullanıldıklarında politik olanın kaybolduğu, anlamın doğallaştığı sözlerdir. Mitler, iktidarın ürettiği "gerçeği” aktarırlar ve esas gerçekleri örneğin eşitsizliği saklayarak, hayalî eşitliği onaylar. ${ }^{66}$ Bunu kurduğu üst-dil aracılığı ile yapar. Tenten'in bu macerasında mitler, okuyucuya dolambaçsız, açık ve seçik bir dille sunulmaktadır. Okur olarak bizler kendimizi maceranın ritmine kaptırmışken, içeriye mitler sızdırılmaktadır. Kolonyal iktidarın otoritesini sağlamlaştırmak ve koruyabilmek adına ürettiği bu mitler, ideolojik bir fabrikasyona dönüşmüştür.

Tenten karakterinin bir mit olması bir yana, bu serüven bir mitler gömüsüdür. $\mathrm{Bu}$ mitler, “öteki” ile "benlik” arasındaki farkı ustalıkla hissettirerek bir söylem oluşturmakta ve propaganda amaçlı kullanılmaktadır. Zamanının Hristiyan ideolojisinin saf bir ürünü olan bu macerada mitler pek çok kez yinelenerek Şarklının/Ötekinin konumu belirlenmekte ve hegemonya kurmaya yardımcı olmaktadırlar. Tenten'de, kolonyalist söylem kendini daha çok "beyaz adamın üstünlügü" miti üzerinden kurmuş, “öteki”ni ise bir eksiklikler mitiüzerinden tanımlamıştır. Böylece "öteki”, "alt-insan” mahiyetine indirgenmiş ve Batı kendi "üstinsan” kimliğini oluşturmuştur. Bu macera aslında Afrika ya da Kongo hakkında değildir, 1930'lu yılların Katolik Belçika’sından Afrika’nın nasıl göründüğ̈ hakkında yani “Öteki” hakkındadır.

\footnotetext{
${ }^{66}$ Barthes, Mythologies, 167.
} 


\section{Berhan ÖZDEMIR EROĞLU}

\section{KAYNAKÇA}

Ana kaynak

Herge. Tintin in the Congo. (San Francisco: Last Grasp, 2002), https:// notendur.hi.is/ sok1/02\%20The\%20Adventures\%20Of\%20Tintin\%20 In\%20The\%20Congo.pdf

\section{Diğer kaynaklar}

Apostolidès, Jean-Marie. "Herge and the Myth of the Superchild," Yale French Studies, no. 111 (2007): 45-57, Son erişim: 20.02.2020, www.jstor. org/stable/20479370

Aydı, Aylin. "Çizgilerdeki Irkçılık," Ankara Üniversitesi Avrupa Toplulukları

Üsküdar University Journal of Social Sciences, 2020; issue: 10, 157-183 Araştırma ve Uygulama Merkezi e-bülten Yıl 4, Sayı 38, (Kasım 2011): 7. Barthes, Roland. Mythologies. London: Vintage Books, 2009.

Bhabha, Homi K. "Of Mimicry and Man: The Ambivalence of Colonial Discourse,” October 28, (1984): 125-133, Son erişim: 17 Şubat 2020, https://dx.doi.org/10.2307/778467

Bhabha, Homi. The Location of Culture. London/New York: Routledge, 1994. https://archive.org/stream/TheLocationOfCultureBHABHA/ the\%20location\%20of\%20culture\%20BHABHA_dju.txt

Cesaire, Aime. Sömürgecilik Üzerine Söylev: Fransız Irkçılığının Fikri Tarihsel Temelleri. Çeviren: Güneş Ayas. İstanbul: Doğu kütüphanesi, 2005.

Chakraborty, Nilanjan. "Not so Comical- Tintin, Popular Culture and the Othering of Spaces", The IUP Journal of English Studies Vol. XI, No. 1, (March 2016): 20-27.

Eagleton, Terry. İdeoloji. Çeviren: Muttalip Özcan. İstanbul: Ayrıntı, 1996. Fanon, Frantz. Yeryüzünün Lanetlileri. Çeviren: Şen Süer. İstanbul: Versus, 2007. 


\section{Kolonyal Söylem Aracı ve Mitler Gömüsü Olarak Bir Çizgi Roman Analizi: Tenten Kongo’da}

Giddens, Anthony ve Philip W. Sutton. Sosyoloji. Çeviren: Ayşe Nilüfer Durakbaşa, Funda Karapehlivan Şenel ve Senem Tüfekçioğlu. İstanbul: Kırmızı, 2008.

Lofficier, Jean-Marc ve Randy Lofficier. Tintin. UK: Harpenden, Herts Pocket Essentials, 2011.

Loomba, Ania. Kolonyalizm - Postkolonyalizm. Çeviren: Mehmet Küçük, İstanbul: Ayrıntı, 2000.

Marx, Karl. “India Under British Rule," Labour Monthly Vol. 7, (December 1925): 717-728.

Mccarthy, Tom. Tenten ve Edebiyatın Gizemi. Çeviren: Cihat Taşçığlu, İstanbul: Notos, 2016.

Said, Edward W. Şarkiyatçılık. Çeviren: Berna Yıldırım, İstanbul: Metis, 2016.

Spivak, Gayatri C. “Can the Subaltern Speak?” (1988): 66-111, Son erişim: 15.02.2020, http://abahlali.org/files/Can_the_subaltern_speak.pdf

Young, Robert. Postcolonialism: An Historical Introduction. UK: Blackwell Publishers, 2001. 
